УдК 621.74.047

Бялик Г. А., Титова Т. М., Наумик В. В.

Запорожский национальный технический университет. Украина, г. Запорожье

\title{
ПРОИЗВОДСТВО ЛИТЫХ СТАЛЕМЕДНЫХ КОМПОЗИТОВ
}

Разработана опытная установка для получения непрерывнолитых металломатричных слитков. Установлено, что в условиях получения указанных изделий присутствует определённая диффузия меди в стальную армирующую вставку, но обратный процесс при этом практически отсутствует. Показано, что наночастицы металлов, температура плавления которых соизмерима с температурой плавления меди, неэффективны в качестве упрочняющей фазы для решения проблемы повышения прочностных свойств медной матрицы без заметного снижения электропроводности. Показана перспективность применения наночастиц карбонитрида титана, бора и карбидов кремния для решения проблемы повыщения прочностных свойств медной матрищы без заметного снижения электропроводности. [dx.doi.org/10.29010/080.10]

Ключевые слова: металломатричный сталемедный композит; армирующая вставка; непрерывное литьё; диффузия; наночастицы; краевой угол смачивания; поверхностное натяжение; прочность; металлическая матрииа; электропроводность. 


\section{Введение}

Техническое использование меди обусловлено её высокой тепло- и электропроводностью, коррозионной устойчивостью в ряде агрессивных сред [1, 2]. Особые свойства меди в значительной мере зависят от чистоты металла по содержанию растворимых примесей, в первую очередь металлических [3].

Медь как электропроводный материал широко применяется в электротехнике и радио-электронике. Однако существенным недостатком меди как конструкционного материала является её небольшая механическая прочность [2]. Наиболее эффективным методом упрочнения металлических материаллов является легирование некоторыми элементами, однако, как было отмечено, даже незначительное содержание последних существенно снижает электропроводность меди. Поэтому перспективным является разработка на основе меди металломатричных композитных материалов, сочетающих высокую электропроводность чистой медной матрицы с повышенной механической прочностью высокопрочного армирующего каркаса.

Простейшим вариантом такого материала является армирование медного изделия, например, проводов контактной сети для электротранспорта высокопрочной стальной вставкой.

\section{Основной материал исследований}

Ля изучения влияния стальной армирующей вставки на жидкотекучесть меди опытные образцы таких изделий получали методом вакуумного всасывания в кварцевые трубки расплавленной меди при температуре $1200^{\circ} \mathrm{C}$. Внутри кварцевых трубок размещали стальную вставку диаметром 3 мм, одна трубка была контрольной и заполнялась чистой медью. Следует отметить, что стальная вставка заметно снизила жидкотекучесть меди (рис. 1).

Охлаждающий эффект стальной вставки на время затвердевания медной матрицы исследовали методом математического моделирования. Результаты исследования приведены на рис. 2.

a

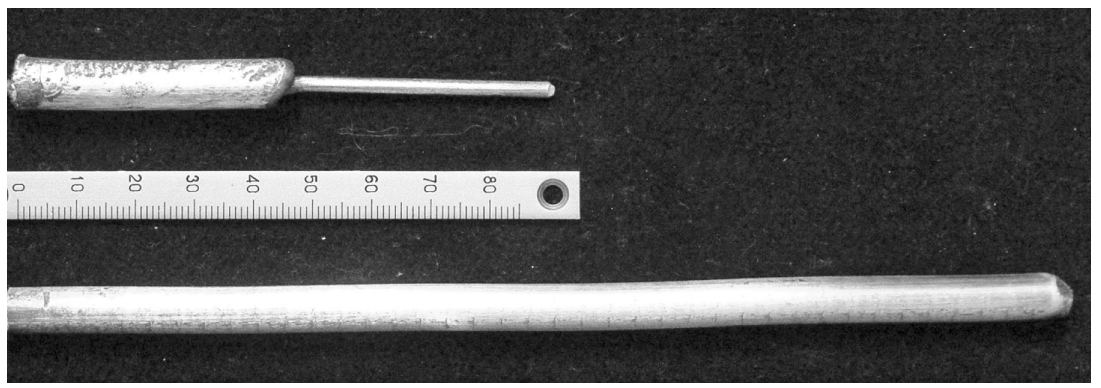

Рис. 1. Влияние стальной армирующей вставки на жидкотекучесть меди: a - образец со стальной армирующей вставкой; б - образец без вставки
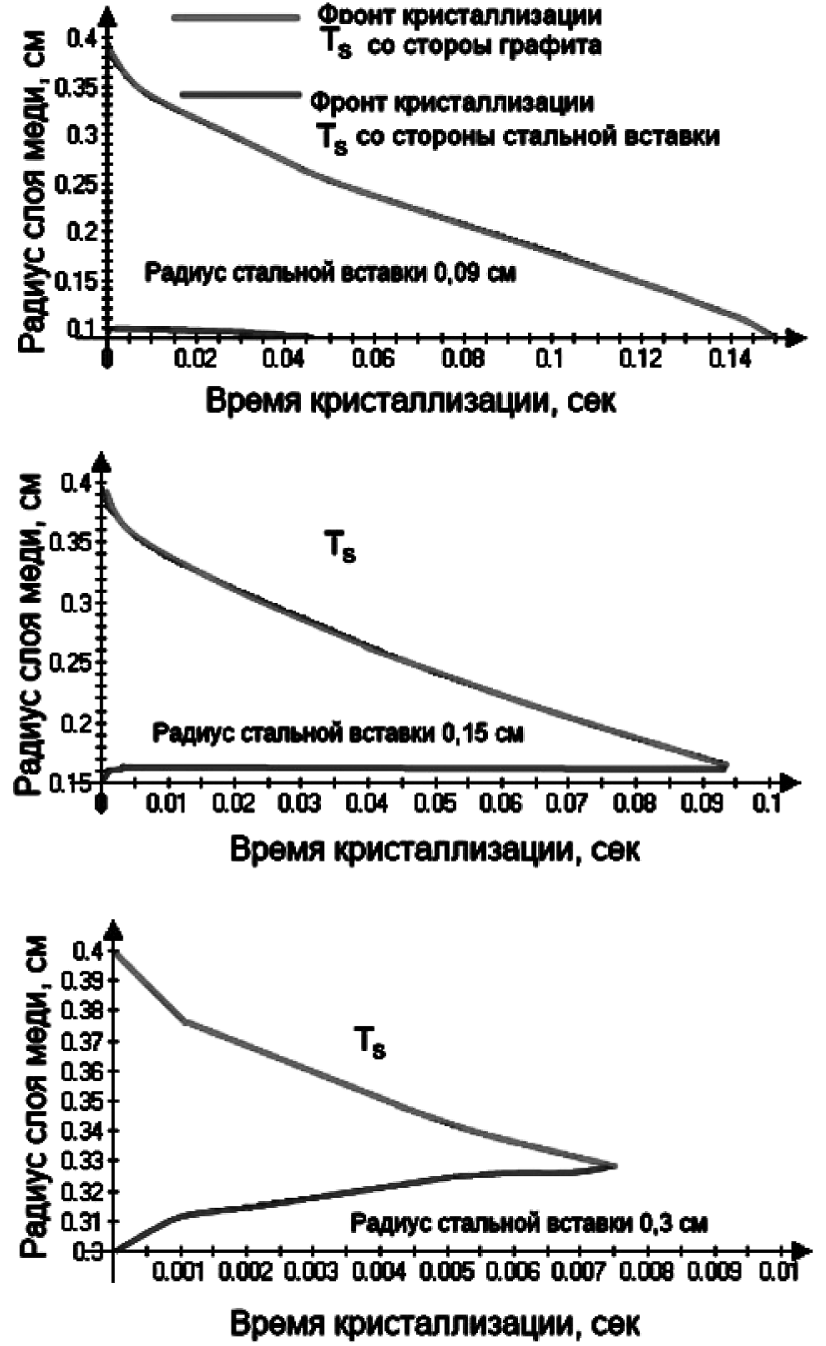

Рис. 2. Кинетика фронта по изотерме $T_{\mathrm{S}}$ затвердевания медного слоя на стальной армирующей вставке [4]

Радиус стальной армирующей вставки оказывает существенное влияние на кинетику кристаллизации медной матрицы и время полной ее кристаллизации.

Анализ результатов исследований, приведенных в работе [4], позволил определить зависимость времени полной кристаллизации медной матрицы армированной металломатричной сталемедной заготовки в зависимости от радиуса стальной вставки (рис. 3).

Полученные данные использовали при разработке опытной установки для получения непрерывнолитого металломатричного проводника для контактной электросети (рис. 4). При этом приняли радиус стальной вставки 0,15 см, радиус медной матрицы 0,4 см, диаметр сталемедной заготовки $1,1 \mathrm{~cm}$. 


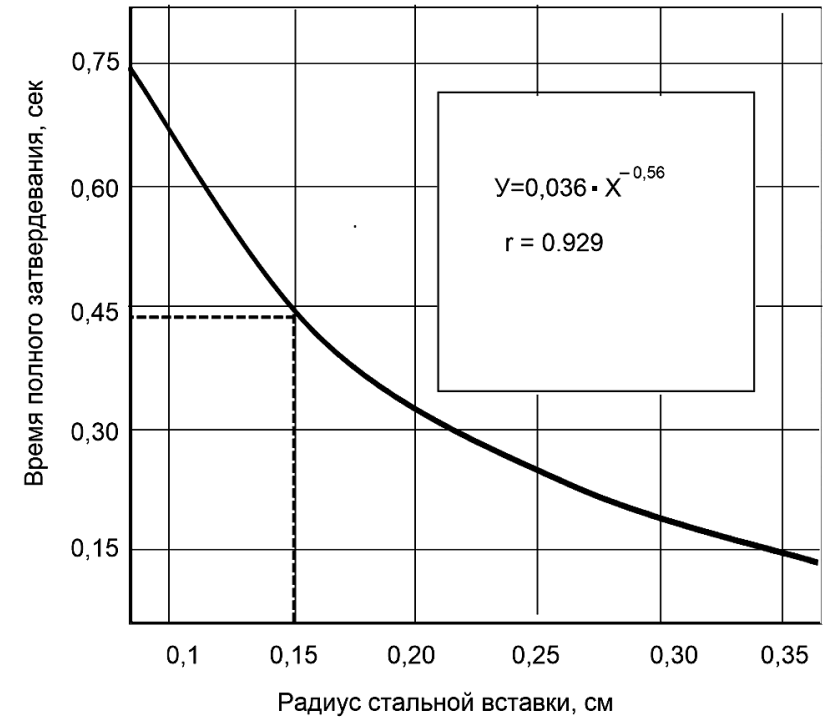

Рис. 3. Зависимость времени полного затвердевания сталемедной заготовки от радиуса стальной армирующей вставки

Установка размещалась в рабочей камере вакуумной индукционной печи. Внутри индуктора 1 установлен графитовый тигель 2. Тигель закрыт графитовой крышкой с направляющим устройством для армирующей стальной вставкой 3 . В нижней части тигля установлен медный водоохлаждаемый кристаллизатор 4 с формообразующей вставкой 5. Ролик 6 непрерывно вытягивает проводник 8 , который наматывается на барабан 7. Стальная армирующая вставка 9 сматывается с барабана 11 через ролик 10, центрируется направляющим устройством и вместе с медной матрицей непрерывно вытягивается из кристаллизатора.

В условиях высокой температуры расплавленной меди (порядка $1200^{\circ} \mathrm{C}$ ), через которую проходит стальная армирующая вставка, возможна диффузия железа в расплавленную медь, что может снизить электропроводность металлической матрицы. Поэтому исследовали микроструктуру металломатричного композитного проводника.

Микроструктура медной матрицы была однородной и не содержала каких-либо включений (рис. 5).

В стальной армирующей вставке в непосредственной близости от медной матрицы наблюдали небольшие включения меди (рис. 6).

Армированные литые материалы на основе меди являются перспективными для изделий электротехнической промышленности, так как сочетают высокую электропроводность, характерную для матрицы из чистой меди, с высокой прочностью армирующей стальной вставки. Однако повышение прочностных характеристик таких материалов связано с увеличением сечения стальной арматуры. Поэтому при разработке указанных материалов актуальной является проблема повышения прочностных свойств медной матрицы без заметного снижения электропроводности.

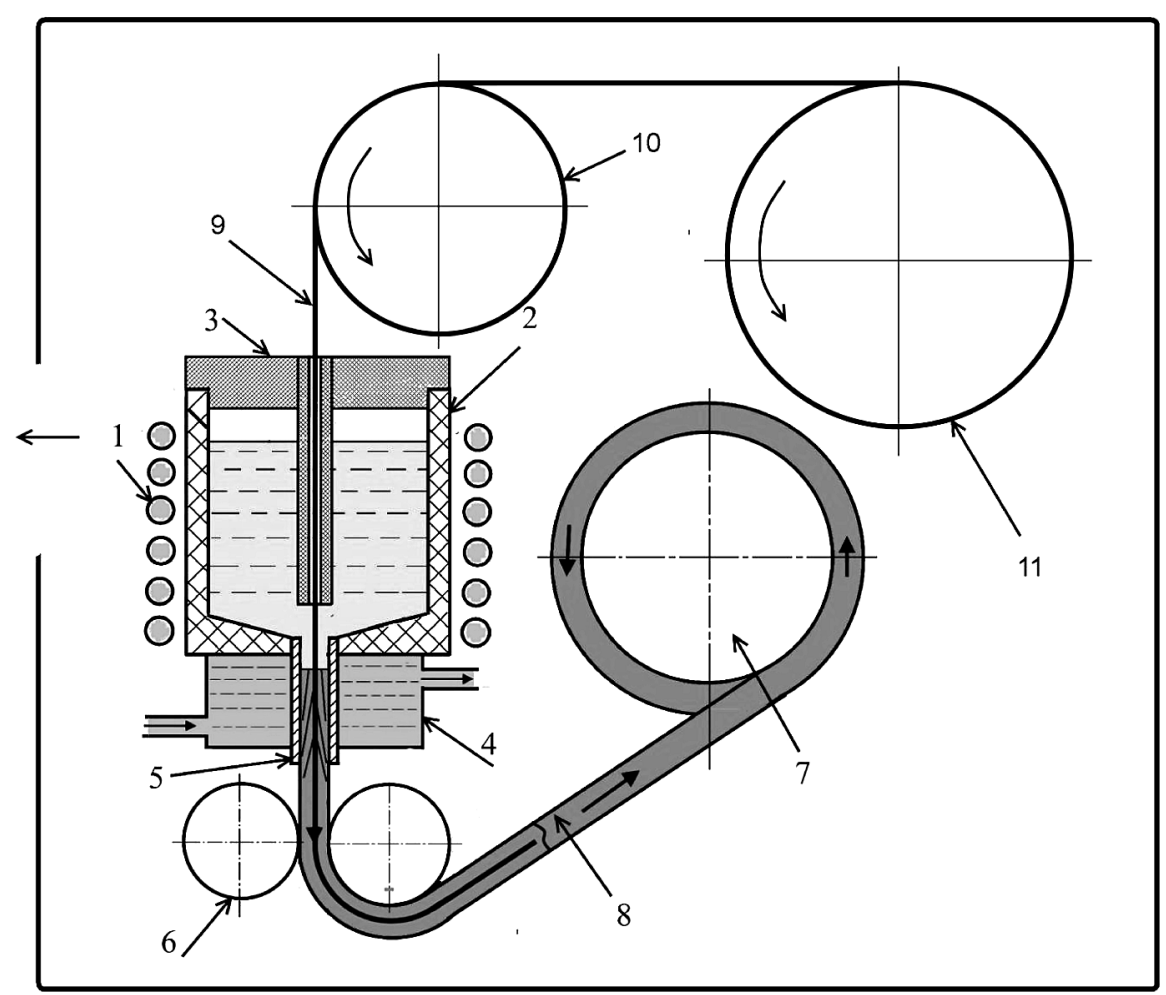

Рис. 4. Установка для получения армированного непрерывнолитого проводника для контактной электросети 


\section{техниоогическиE'TC 3/2017}

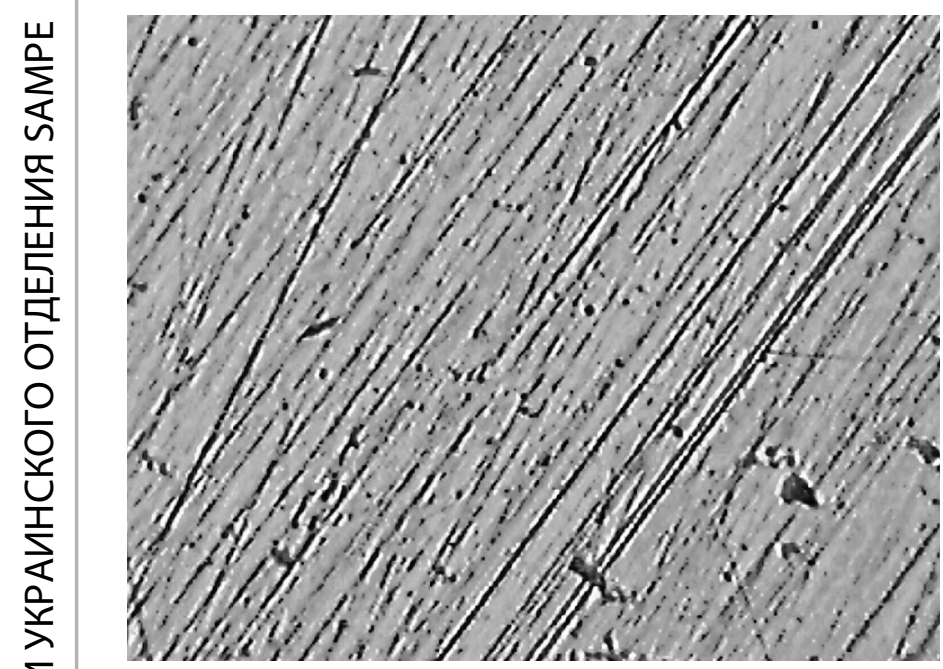

Рис. 5. Микроструктура медной матрицы

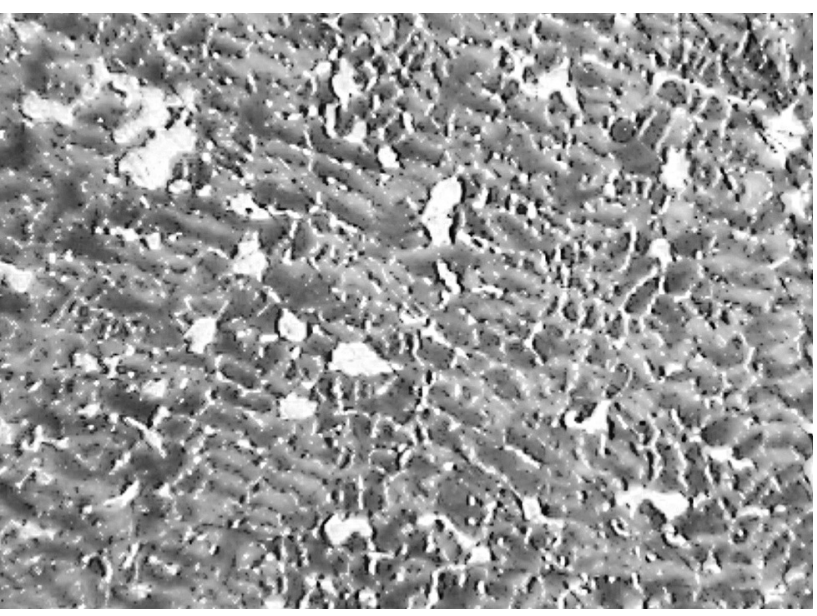

Рис. 6. Включения меди в стальной армирующей вставке в непосредственной близости от медной матрицы

Принципиально эта задача может быть решена за счет дисперсионного упрочнения. При этом необходимо, чтобы в медной матрице образовалась вторая фаза в виде очень мелких и однородно распределенных частиц, имеющих некогерентную поверхность раздела с матрицей. Образование частиц второй фазы путем легирования меди некоторыми элементами, например, бериллием, неизбежно приводит к снижению электропроводности меди. Более рациональным является введение в расплавленную медь наночастиц и обеспечение их равномерного распределения по сечению матрицы. Увеличение предела текучести меди при упрочнении ее наночастицами можно рассчитать по формуле, приведенной в работе [5]:

$$
\sigma_{\mathrm{T}}=\frac{G \cdot b}{R},
$$

где $G$ - модуль сдвига, для меди $G=48000$ МПа;

$b$ - вектор Бюргерса, $b=2,56 \times 10^{-9}$ м;
$R$ - расстояние между наночастицами, м.

В таблице 1 приведены результаты расчетов по формуле (1).

Для наночастиц следует учитывать понижение температуры плавления маленьких кристалликов как функцию их размера. Разность между точкой плавления маленького кристаллика и нормальной (макроскопической) точкой плавления выражается уравнением Гиббса-Томсона:

$$
\frac{T_{\infty}-T_{r}}{T_{\infty}}=\frac{\Delta T}{T_{\text {пл }}},
$$

где $T_{\infty}$ - нормальная температура плавления;

$\Delta T$ - разность между точкой плавления микрои макрокристалла;

$T_{r}$ - температура плавления, при которой плавится кристалл с радиусом $r$.

Понижение точки плавления для некоторых металлов приведено в работе [6]. Наиболее близким к меди по температуре плавления и некоторым другим свойствам (теплопроводность, электропроводность, одинаковый структурный тип и пространственная группа, близкие атомные радиусы) из приведенных металлов является серебро. Логично предположить, что и значения $T_{r}$ меди и серебра будут близкими.

На рис. 7 приведена зависимость снижения температуры плавления от размера кристалла серебра, построенная по данным, приведенным в работе [6]. Кристаллы твердого металла, размеры которых соизмеримы с наночастицами, способны растворяться в жидком металле в течение короткого промежутка времени. Следовательно, наночастицы металлов, температура плавления которых соизмерима с температурой плавления меди, неэффективны в качестве упрочняющей фазы.

Эта зависимость соответствует уравнению регрессии:

$$
\Delta T=149470,296 \cdot r^{-1,025} \quad r=-0,999
$$

Таблица 1

\section{Влияние расстояния между наночастицами на предел текучести меди}

\begin{tabular}{|c|c|}
\hline $\begin{array}{c}\text { Расстояние между } \\
\text { наночастицами, м }\end{array}$ & $\begin{array}{c}\text { Увеличение предела } \\
\text { текучести, МПа }\end{array}$ \\
\hline $10^{-2}$ & 0,0122 \\
\hline $10^{-3}$ & 0,12288 \\
\hline $10^{-4}$ & 1,2288 \\
\hline $10^{-5}$ & 12,288 \\
\hline $10^{-6}$ & 122,88 \\
\hline $10^{-7}$ & 1228,8 \\
\hline
\end{tabular}




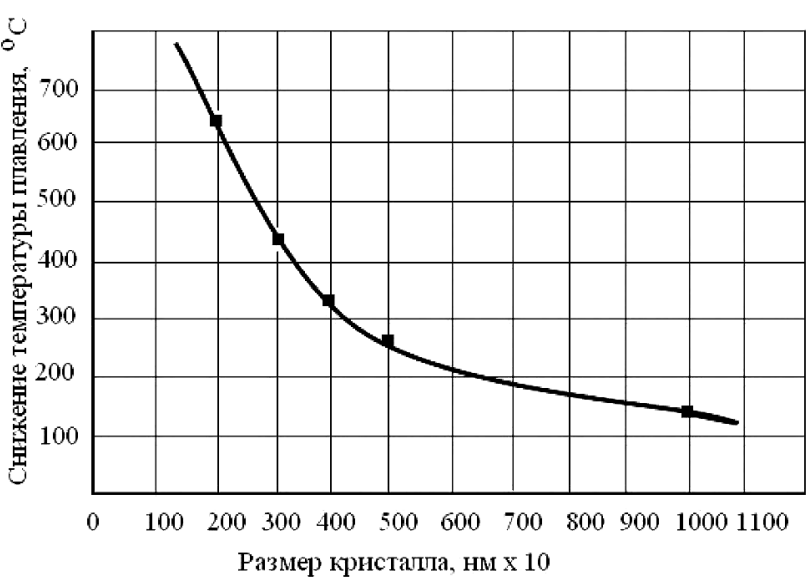

Рис. 7. Зависимость снижения температуры плавления от размера кристалла

Для армированных отливок существенное влияние на качество последних оказывают поверхностные явления на границах раздела «жидкий металл - твердое тело». Надежное соединение матрицы и стальной армирующей вставки в значительной степени определяется смачиванием жидким металлом твердого тела. Условие смачивания: поверхностное натяжение на границе жидкости с твердым телом должно быть меньше поверхностного натяжения твердого тела с газовой фазой. Условия равновесия на границе раздела трех фаз определяются следующим уравнением:

$$
\sigma_{\mathrm{T}-\mathrm{\Gamma} \_}=\sigma_{\mathrm{T}-ж}+\sigma_{\text {ж-Г }} \cdot \cos \theta,
$$

где $\theta$ - угол, образованный касательной к границе

раздела «жидкость - газ» (ж-г) и границей раздела «твердое тело - жидкость» (т - ж) (краевой угол смачивания) [3].

Работа адгезии $A_{\text {адг }}$ определяется по уравнению:

$$
\mathrm{A}_{\text {адг }}=\sigma_{\mathrm{T}-\Gamma_{-} \sigma}+\sigma_{\text {ж-Г }}-\sigma_{\text {т-ж}},
$$

или

$$
\mathrm{A}_{\text {адг }}=\sigma_{\text {ж-г }} \cdot(1-\cos \theta) .
$$

Работа адгезии тем больше, чем меньше межфазное натяжение.

Растекание жидкости по поверхности твердого тела может быть выражено через работу адгезии и работу когезии. Условие растекания: работа адгезии должна быть больше работы когезии.

Растекание жидкости по поверхности твердого тела характеризуется коэффициентом растекания $K_{\text {ж-т раст }}$ :

$$
\mathrm{K}_{\text {ж-т_раст }}=\sigma_{\text {Ж-Г }} \cdot(\cos \theta-1) .
$$

В свою очередь $\cos \theta$ является функцией поверхностного натяжения $\sigma_{ж-r}$ :

$$
\cos \theta=\frac{\sigma_{\mathrm{T}-\Gamma}-\sigma_{\mathrm{T}-\%}}{\sigma_{\text {Ж }-\Gamma}} .
$$

Необходимым условием равномерного распределения наночастиц в расплаве является минимальная взаимная адгезия и большая адгезия к расплаву.

Вместе с тем, введение наночастиц не должно увеличивать краевой угол смачивания и поверхностное натяжение расплава, так как в этом случае нарушается прочность соединения медной матрицы и армирующей стальной вставки.

Провели эксперимент по определению краевого угла смачивания расплавом меди корундовой подложки. Расплав модифицировали наночастицами меди, алюминия, карбидом кремния, карбонитридами титана и бора. Результаты определения краевого угла смачивания приведены в таблице 2 .

Модифицирование наночастицами меди заметного влияния на краевой угол смачивания не оказало. Модифицирование алюминием снизило краевой угол смачивания. В наибольшей степени снизили краевой угол смачивания наночастицы карбонитрида титана, бора и карбида кремния. Эти модификаторы можно рассматривать как перспективные для дальнейших исследований.

\section{Выводы}

На основании анализа полученной зависимости времени полного затвердевания сталемедной заготовки от радиуса стальной армирующей вставки разработана опытная установка для получения непрерывнолитых металломатричных слитков.

Установлено, что в условиях получения указанных изделий присутствует определённая диффузия

Таблица 2

Краевой угол смачивания расплавом меди подложки из корунда (метод лежащей капли)

\begin{tabular}{|c|c|c|c|c|c|c|}
\hline o образца & $\mathbf{1}$ & $\mathbf{2}$ & $\mathbf{3}$ & $\mathbf{4}$ & $\mathbf{5}$ & $\mathbf{6}$ \\
\hline Модификатор & $\begin{array}{c}\text { без моди- } \\
\text { фикатора }\end{array}$ & $\begin{array}{c}\text { карбонитрид } \\
\text { титана }\end{array}$ & $\begin{array}{c}\text { карбонитрид } \\
\text { бора }\end{array}$ & $\begin{array}{c}\text { медь, } \\
\text { наночастицы }\end{array}$ & алюминий & $\begin{array}{c}\text { карбид } \\
\text { кремния }\end{array}$ \\
\hline $\begin{array}{c}\text { Краевой угол } \\
\text { смачивания, } \theta, \text { град. }\end{array}$ & 124,5 & 83 & 90 & 128 & 107 & 84,5 \\
\hline
\end{tabular}


меди в стальную армирующую вставку, но обратный процесс при этом практически отсутствует микроструктура медной матрицы получена однородной и не содержит каких-либо включений.

Показано, что наночастицы металлов, температура плавления которых соизмерима с температурой плавления меди, неэффективны в качестве упрочняющей фазы для решения проблемы повышения прочностных свойств медной матрицы без заметного снижения электропроводности.

Изучено влияние поверхностных явлений на границах раздела «жидкий металл - твердое тело» на качество армированных отливок. Поскольку для сохранения прочности соединения медной матрицы и армирующей стальной вставки введение наночастиц не должно увеличивать краевой угол смачивания и поверхностное натяжение расплава, провели исследования и установили, что карбонитрид титана, бора и карбид кремния можно рассматривать как перспективные для этой цели, как в наибольшей степени снижающие краевой угол смачивания.

\section{Литература}

[1] Производство отливок из сплавов цветных металлов: [учебник для вузов] / Курдюмов А. В., Пикунов М. В., Чурсин В. М., Бибиков Е. Л. - М.: Металлургия, 1986. $-416 \mathrm{c}$.

[2] Бобылёв А. В. Механические и технологические свойства металлов: [справочник] / Бобылёв А. В. М.: Металлургия, 1980. - 296 с.

[3] Буров А. В. Литьё слитков меди и медных сплавов / Буров А. В. - М.: Металлургия, 1972. - 176 с.

[4] Математическое моделирование процесса затвердевания медных и сталемедных заготовок при непрерывном литье / Е. С. Титова, А. Н. Сокол, Т. М. Титова, А. П. Огурцов, В. П. Полетаев // Прогрессивные технологии и системы машиностроения. 2011 г. - № 2. - С. 274-278.

[5] Статическая прочность и механика разрушения сталей / Под ред. В. Даля, В. Антона, - М.: Металлургия, 1986. -566 с.

[6] Мейер К. Физико-химическая кристаллография / К. Мейер. - М.: Металлургия, 1972. - 480 с.

Byalik G. A., Titova T. M., Naumik V. V.

Zaporozhye National Technical University. Ukraine, Zaporozhye

\section{THE CAST STEEL-COPPER COMPOSITES PRODUCTION}

A pilot equipment has been developed for the production of continuously cast metal-ingots. It is established that under the conditions of obtaining these products there is a certain diffusion of copper into the steel reinforcing insert, but the reverse process is practically absent. It is shown that metal nanoparticles whose melting temperature is commensurable with the melting point of copper are ineffective as a strengthening phase for solving the problem of increasing the strength properties of a copper matrix without appreciably reducing the electrical conductivity. The perceptivity of using nanoparticles of titanium carbonitride, boron and silicon carbides is shown to solve the problem of increasing the strength properties of a copper matrix without appreciably reducing the electrical conductivity. [dx.doi.org/10.29010/080.10]

Keywords: metal matrix steel-copper composite; reinforcing insert; continuous casting; diffusion; nanoparticles; contact angle; surface tension; strength; metal matrix; electrical conductivity.

\section{References}

[1] Proizvodstvo otlivok iz splavov tsvetnyih metallov: [uchebnik dlya vuzov] / Kurdyumov A. V., Pikunov M. V., Chursin V. M., Bibikov E. L. - M.: Metallurgiya, 1986. - 416 s.

[2] Bobyilyov A. V. Mehanicheskie i tehnologicheskie svoystva metallov: [spravochnik] / Bobyilyov A. V. - M.: Metallurgiya, 1980. - $296 \mathrm{~s}$.

[3] Burov A. V. Lityo slitkov medi i mednyih splavov / Burov A. V. - M.: Metallurgiya, 1972. - $176 \mathrm{~s}$.

[4] Matematicheskoe modelirovanie protsessa zatverdevaniya mednyih i stalemednyih zagotovok pri nepreryivnom lite / E. S. Titova, A. N. Sokol, T. M. Titova, A. P. Ogurtsov, V. P. Poletaev // Progressivnyie tehnologii i sistemyi mashinostroeniya. - 2011 g. - № 2. - S. 274-278.

[5] Staticheskaya prochnost i mehanika razrusheniya staley / Pod red. V. Dalya, V. Antona, - M.: Metallurgiya, 1986. - $566 \mathrm{~s}$.

[6] Meyer K. Fiziko-himicheskaya kristallografiya / K. Meyer. - M.: Metallurgiya, 1972. - $480 \mathrm{~s}$. 